University of Wollongong

Research Online

Faculty of Engineering - Papers (Archive)

Faculty of Engineering and Information

Sciences

$1-1-2010$

\title{
Nonlinear analysis for a single vertical drain including the effects of preloading considering the compressibility and permeability of the soil
}

Buddhima Indraratna

University of Wollongong, indra@uow.edu.au

Xueyu Geng

University of Wollongong, xgeng@uow.edu.au

Cholachat Rujikiatkamjorn

University of Wollongong, cholacha@uow.edu.au

Follow this and additional works at: https://ro.uow.edu.au/engpapers

Part of the Engineering Commons

https://ro.uow.edu.au/engpapers/879

\section{Recommended Citation}

Indraratna, Buddhima; Geng, Xueyu; and Rujikiatkamjorn, Cholachat: Nonlinear analysis for a single vertical drain including the effects of preloading considering the compressibility and permeability of the soil 2010, 147-156.

https://ro.uow.edu.au/engpapers/879

Research Online is the open access institutional repository for the University of Wollongong. For further information contact the UOW Library: research-pubs@uow.edu.au 


\title{
Nonlinear analysis for a single vertical drain including the effects of preloading considering the compressibility and permeability of the soil
}

\author{
Buddhima Indraratna $^{1}$, FASCE, Xueyu Geng ${ }^{2}$ and Cholachat Rujikiatkamjorn ${ }^{3}$ \\ ${ }^{1}$ Professor of Civil Engineering, Faculty of Engineering, Univ. of Wollongong, \\ Wollongong City, NSW 2522, Australia (corresponding author). E-mail: \\ indra@uow.edu.au \\ ${ }^{2}$ Research Fellow, Faculty of Engineering, Univ. of Wollongong, Wollongong City, \\ NSW 2522, Australia. \\ ${ }^{3}$ Lecturer, Faculty of Engineering, Univ. of Wollongong, Wollongong City, NSW \\ 2522, Australia.
}

\begin{abstract}
In this paper, the free strain radial consolidation theory incorporating the changes of compressibility and permeability of the soil with the change in effective stress via time dependent surcharge preloading is presented. In contrast to the conventional analysis, the current study highlights the nonlinear characteristics of the soil during the consolidation process. A comparison of the nonlinear radial consolidation model, with the conventional theory and the equal strain theory i.e. constant volume compressibility, $m_{v}$ and constant coefficient of horizontal permeability, $k_{h}$ is presented. Finally, a case history at Muar coastal plain, Malaysia is analysed on the basis of the current solution. This case history indicates improved accuracy of the predictions in relation to the field measurements and observations.
\end{abstract}

Keywords: nonlinear material properties; vertical drain; compressibility; permeability, time dependent surcharge loading;

\section{INTRODUCTION}

The system of vertical drain is one of the most popular methods of increasing the shear strength of soil, and of reducing its post construction settlement by shortening the drainage path. The well-known radial consolidation theory was proposed by Barron (1948), who assumed two types of vertical strain that might occur in a clay layer. One type is free vertical strain, which results from a uniform distribution of surface load. The other is equal strain vertical strain, which results from imposing the same vertical deformation on the surface of uniform soil. For the free strain theory, Yoshikuni and Nakanodo (1974) extended Barron's solution to give a rigorous solution, taking the well-resistance into consideration. Zhu and Yin (2001) have presented a solution based on the theory of free strain, subjected to ramp loading. For equal strain theory, Indraratna et al. (2005a, b) and Rujikiatkamjorn et al. $(2007,2009)$ have made an attempt to analyse the vacuum consolidation behaviour of soil based on the equal strain assumptions. However, all the existing theories still 
consider the coefficients of permeability and compressibility to be constant during the consolidation process (Basak and Madhav 1978; Cai et al. 2007; Davis and Raymond. 1965; Geng et al. 2006; Xie et al. 2002). Using the equal strain theory, Olson (1977) obtained a solution for the case of vertical drain under a ramp load, and Lekha et al. (1998) proposed a modified approach capturing radial drainage. Recently, Geng (2008) presented some primary analytical results on the nonlinear consolidation theory considering the soil compressibility. Indraratna et al. (2005c) analysed a system of vertical drain, with surcharge loading incorporating the varying compressibility and horizontal permeability of the soil based on the equal strain theory. However, neither of them actually has given the results considering the effects caused by time dependent surcharge loading. This paper presents rigorous solution for the same.

\section{RADIAL CONSOLIDATION ANALYSIS}

The axisymmetric unit cell is shown in Figure 1. Following the free strain approach, this paper presents a particular form of the generalized governing equation, capable of yielding a large class of solutions for surcharge loading with prefabricated vertical drains (PVDs), which can handle the permeability and compressibility changes with effective stress. The normalised time factor, $T_{v c}$ is suggested. The differential equation for the vertical strain and the dissipation of excess pore water pressure using the free strain assumption can be expressed by:

$$
\left\{\begin{array}{l}
\frac{\partial \varepsilon_{v}}{\partial t}=\frac{1}{1+e_{0}} \frac{\partial e}{\partial t} \\
-\frac{1}{r \gamma_{w}} \frac{\partial}{\partial r}\left[r k_{h} \frac{\partial u}{\partial r}\right]-\frac{1}{\gamma_{w}} \frac{\partial}{\partial z}\left[k_{v} \frac{\partial u}{\partial z}\right]=\frac{\partial \varepsilon_{v}}{\partial t} \quad r_{w} \leq r \leq r_{e}
\end{array}\right.
$$

The change in void ratio with permeability and effective stress (Fig. 2) can be expressed by:

$$
\begin{aligned}
& e-e_{0}=c_{c} \log \left(\sigma_{0}^{\prime} / \sigma^{\prime}\right) \\
& e-e_{0}=c_{k} \log \left(k_{h} / k_{h 0}\right) \\
& e-e_{0}=c_{2} \log \left(k_{h} / k_{h 0}\right)
\end{aligned}
$$

where, $\varepsilon_{v}$ is the vertical strain, $u$ is excess pore water pressure, $t$ is time, $r$ is the radial coordinate, $z$ is the vertical coordinate, $\gamma_{w}$ is the unit weight of water, $e$ is the void ratio, $e_{0}$ is the initial void ratio, $C_{c}$ is the compression index, $C_{k}$ is the vertical hydraulic conductivity index, $C_{2}$ is the horizontal hydraulic conductivity index, $k_{h}$ and $k_{v}$ are the horizontal and vertical permeability respectively, $\sigma_{0}^{\prime}$ is the initial effective stress, $\sigma^{\prime}$ is the effective stress, $k_{h 0}$ is the initial horizontal permeability coefficient, $k_{v 0}$ is the initial coefficient of vertical permeability stress., $r_{w}$ is the radius of the drain, $r_{e}$ is the radius of equivalent 
cylindrical block of soil.

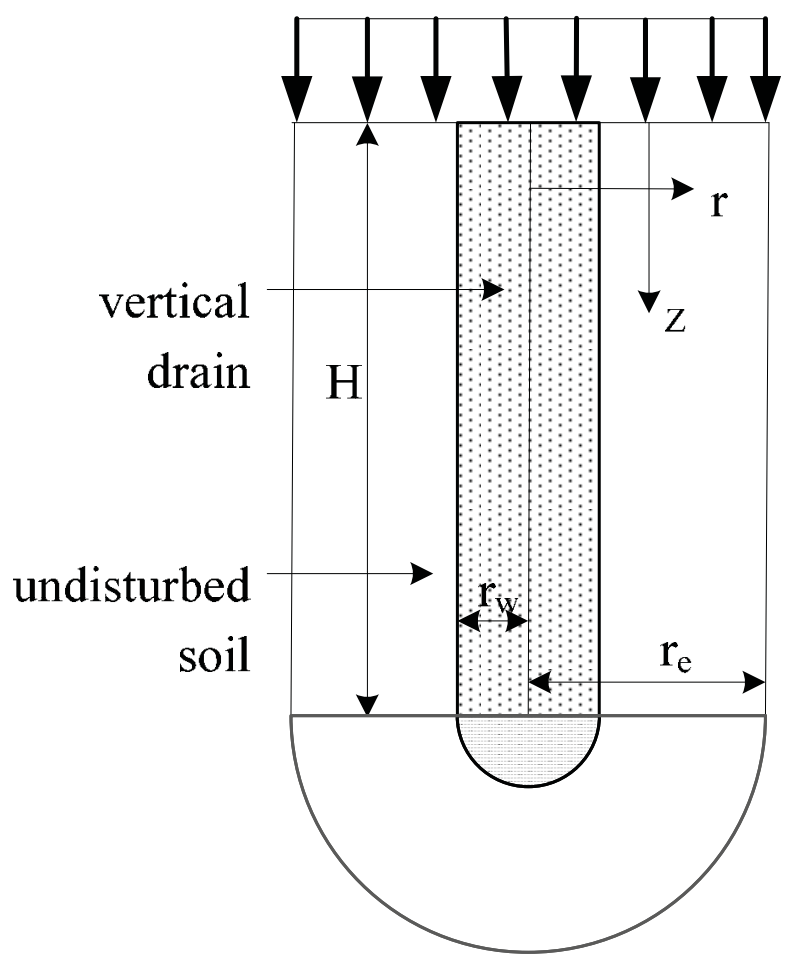

Figure 1. Typical cylindrical cell representing a vertical drain surrounded by undisturbed soil with time-dependent surcharge preloading.

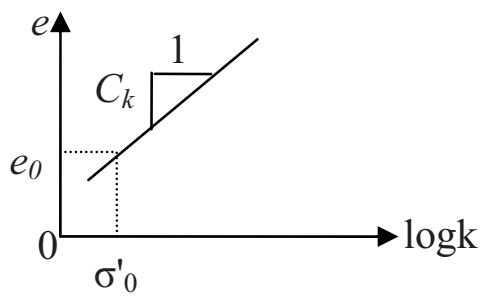

(a)

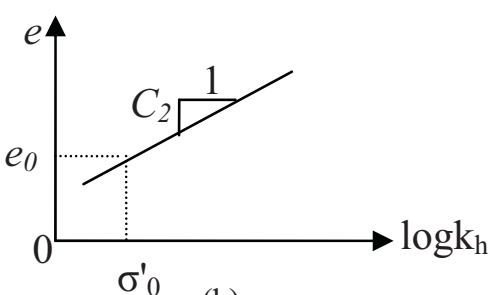

(b)

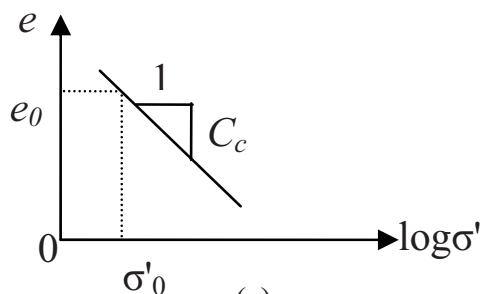

(c)

Figure 2. Constitutive relationships of compressibility and permeability of the soil layer: (a) hydraulic conductivity in the vertical direction; (b) hydraulic conductivity in the horizontal direction; (c) compressibility of the soil

Substituting Equations (2)-(4) into Equation (1), and assuming that the decrease in permeability is proportional to the decrease in compressibility during the soil consolidation; and also that the distribution of initial effective stress is constant with depth, the governing equation can be then written as: 


$$
\frac{1}{r \gamma_{w}} \frac{\partial}{\partial r}\left[r k_{h 0}\left(\frac{\sigma_{0}^{\prime}}{\sigma^{\prime}}\right) \frac{\partial u}{\partial r}\right]+\frac{1}{\gamma_{w}} \frac{\partial}{\partial z}\left[k_{v 0}\left(\frac{\sigma_{0}^{\prime}}{\sigma^{\prime}}\right) \frac{\partial u}{\partial z}\right]=\frac{C_{c}}{\left(1+e_{0}\right) \ln 10} \frac{1}{\sigma^{\prime}}\left(\frac{\partial u}{\partial t}-\frac{d q}{d t}\right)
$$

The boundary and initial conditions for vertical and horizontal drainage are given by:

$$
\left\{\begin{array}{l}
\sigma^{\prime}(r, 0, t)=q(t)+\sigma_{0}^{\prime},\left.\frac{\partial \sigma^{\prime}}{\partial z}\right|_{z=H}=0 \\
\sigma^{\prime}\left(r_{w}, z, t\right)=q(t)+\sigma_{0}^{\prime},\left.\frac{\partial \sigma^{\prime}}{\partial r}\right|_{r=r_{e}}=0
\end{array}\right.
$$

At $t=0 \quad u(r, z, 0)=q_{0}$

where $q_{0}$ is the initial surcharge preloading loading.

Based on separating the variable approach, the solution based on Equation (5) with the initial and boundary conditions can be expressed as:

$$
u=[1-\exp (\omega)] N_{\sigma} /\left(N_{\sigma}-1\right)
$$

where as,

$$
\omega=\sum_{m, n=1}^{\infty} A_{m n i}(T) R_{m}(R) \sin \left(\lambda_{n} Z\right)
$$

in which,

$$
\begin{aligned}
& A_{m n-\text { ramp } 1}(T)=G_{m n} \cdot\left[\ln T+\sum_{k=1}^{\infty}\left(\frac{\mu_{m}^{2}+\lambda_{m}^{2} L}{\mu_{1}^{2}+\lambda_{1}^{2} L}\right)^{k} \frac{T_{v c}^{k}\left(T^{k}-1\right)}{\left(N_{\sigma}-1\right)^{k} k ! k}\right] \quad\left(0 \leq T_{v} \leq T_{v c}\right) \\
& A_{m n-\operatorname{ramp} 2}(T)=G_{m n} \cdot\left[\ln N_{\sigma}+\sum_{k=1}^{\infty}\left(\frac{\mu_{m}^{2}+\lambda_{m}^{2} L}{\mu_{1}^{2}+\lambda_{1}^{2} L}\right)^{k} \frac{T_{v c}^{k}\left(N_{\sigma}^{k}-1\right)}{\left(N_{\sigma}-1\right)^{k} k ! k}\right] \quad\left(T_{v c} \leq T_{v}\right) \\
& G_{m n}=\frac{B_{m n}}{\lambda_{n}} \exp \left(-\frac{\mu_{m}^{2}+\lambda_{m}^{2} L}{\mu_{1}^{2}+\lambda_{1}^{2} L} T_{v}\right) \exp \left(-\frac{\mu_{m}^{2}+\lambda_{m}^{2} L}{\mu_{1}^{2}+\lambda_{1}^{2} L} \frac{T_{v c}}{N_{\sigma}-1}\right) \quad, \quad B_{m n}=\frac{4 r_{w} R_{m}^{\prime}\left(r_{w}\right) \pi^{2}}{4-\left[\pi r_{w} R_{m}^{\prime}\left(r_{w}\right)\right]^{2}}, \\
& N_{\sigma}=1+\frac{q_{u}}{\sigma_{0}^{\prime}}, T=\frac{T_{v c}+\left(N_{\sigma}-1\right) T_{v}}{T_{v c}}, T_{v c}=\frac{\left(\mu_{1}^{2}+\lambda_{1}^{2} L\right) C_{h 0} t_{c}}{r_{w}^{2}} .
\end{aligned}
$$

where, $Z=z / H$ is a dimensionless vertical coordinate, $R=r / r_{w}$ is the dimensionless radial coordinate, $T_{v}$ is the dimensionless time factor. The determinations of $T_{v}, R_{m}, \mu_{m}$ and $\lambda_{n}$ are discussed below.

$R_{m}$ can be expressed in terms of Bessel function (Moshier, 1989, Zhu and 
Yin 2001) of the first kind $\left(J_{0}, J_{1}\right)$ and of the second kind $\left(Y_{0}, Y_{1}\right)$ as follows:

$$
R_{m}(R)=Y_{1}\left(N \mu_{m}\right) J_{0}\left(\mu_{m} R\right)-J_{1}\left(N \mu_{m}\right) Y_{0}\left(\mu_{m} R\right)
$$

where, $N=\frac{r_{e}}{r_{w}}$.

$$
r_{w} R_{m}^{\prime}\left(r_{w}\right)=\mu_{m}\left[J_{1}\left(N \mu_{m}\right) Y_{1}\left(\mu_{m}\right)-Y_{1}\left(N \mu_{m}\right) J_{1}\left(\mu_{m}\right)\right]
$$

The quantity $\mu_{m}$ is the $m^{\text {th }}$ positive root of the following equation:

$$
Y_{1}\left(N \mu_{m}\right) J_{0}\left(\mu_{m}\right)-J_{1}\left(N \mu_{m}\right) Y_{0}\left(\mu_{m}\right)=0
$$

where, $T=\frac{\left(\mu_{1}^{2}+\lambda_{1}^{2} L\right) C_{h 0} t}{r_{w}^{2}}, \lambda_{n}=n \pi-\frac{\pi}{2}, C_{h 0}=\frac{k_{h 0}}{\gamma_{w} m_{v 0}}, m_{v 0}=\frac{C_{c}}{\left(1+e_{0}\right) \sigma_{0}^{\prime} \ln 10}$.

The settlement at any location in the soil is given by:

$$
S=\int_{r_{w}}^{r_{e}} \frac{2 \pi r}{\pi\left(r_{w}^{2}-r_{e}^{2}\right)} \int_{0}^{z} \varepsilon d z d r=\frac{2 C_{c} \cdot H}{\left(N^{2}-1\right)\left(1+e_{0}\right) \ln 10} \frac{N^{2}-1}{2} \cdot \ln \left(1+\frac{q_{u}}{\sigma_{0}^{\prime}}\right) \cdot Z
$$

The average degree of consolidation $(U)$ can be defined either in terms of effective stress or strain. While the average degree of consolidation, defined in terms of stress shows the rate of increase in effective stress or the rate of excess pore water pressure dissipation. The average degree of consolidation defined in terms of strain indicates the rate of settlement, the average degree of consolidation can be defined in terms of effective stress (i.e. excess pore water pressure dissipation) as:

$$
U_{p}=\frac{\int_{0}^{H} \int_{1}^{R} R[q(t)-u] d R d z}{\int_{0}^{H} \int_{1}^{N} R q_{u} d R d z}= \begin{cases}\frac{2 T \int_{1}^{N} \int_{0}^{1} R \mathrm{e}^{\omega_{r a n p l}} d Z d R}{\left(N_{\sigma}-1\right)\left(N^{2}-1\right)}-\frac{1}{N_{\sigma}-1} & \left(0 \leq T_{v} \leq T_{v c}\right) \\ \frac{2 N_{\sigma} \int_{1}^{N} \int_{0}^{1} R \mathrm{e}^{\omega_{r a n p 2}} d Z d R}{\left(N_{\sigma}-1\right)\left(N^{2}-1\right)}-\frac{1}{N_{\sigma}-1} & \left(T_{v c} \leq T_{v}\right)\end{cases}
$$
by:

The average degree of consolidation in terms of settlement can be expressed

$$
U_{s}=\frac{\int_{0}^{H} \int_{r_{e}}^{r_{w}} r \varepsilon d r d z}{\int_{0}^{H} \int_{r_{e}}^{r_{w}} r \varepsilon_{f} d r d z}= \begin{cases}\frac{\ln T}{\ln N_{\sigma}}-\sum_{m, n=1}^{\infty} \frac{4 A_{m n-r a m p 1}(T) r_{w} R_{m}^{\prime}\left(r_{w}\right)}{\left(N^{2}-1\right) \mu_{m}(2 n-1) \pi \ln N_{\sigma}} & \left(0 \leq T_{v} \leq T_{v c}\right) \\ 1-\sum_{m, n=1}^{\infty} \frac{4 A_{m n-- \text { ramp } 2}(T) r_{w} R_{m}^{\prime}\left(r_{w}\right)}{\left(N^{2}-1\right) \mu_{m}(2 n-1) \pi \ln N_{\sigma}} & \left(T_{v c} \leq T_{v}\right)\end{cases}
$$




\section{APPLICATION TO A CASE HISTORY}

A number of test embankments on the Muar coastal plain were constructed by the Malaysian Highway Authority. One of the trial embankments was constructed with PVDs installed in a triangular pattern at a spacing of $1.3 \mathrm{~m}$ (Indraratna et al. 1994). The details of the drain geometry are given in Table 1. The geotechnical parameters of the subsoil layers obtained from standard oedometer tests are listed in Table 2.

Table 1. Geometric parameters of the vertical drain system for a Muar clay embankment.

\begin{tabular}{c|c}
\hline Drain parameters & Details \\
\hline Installation pattern and spacing & $\begin{array}{c}\text { Triangular } \\
\text { and } 1.3 \mathrm{~m}\end{array}$ \\
\hline Diameter of influence zone, $r_{e}(\mathrm{~m})$ & 0.6825 \\
\hline Equivalent drain diameter, $r_{w}(\mathrm{~m})$ & 0.035 \\
\hline
\end{tabular}

Table 2. Soil parameters used in analysis

\begin{tabular}{c|c|c|c|c|c|c|c}
\hline $\begin{array}{c}\text { Depth } \\
(\mathbf{m})\end{array}$ & $\begin{array}{c}k_{h 0} \times \mathbf{1 0}^{-9} \\
(\mathbf{m} / \mathbf{s})\end{array}$ & $\begin{array}{c}k_{v 0} \\
(\mathbf{m} / \mathbf{s})\end{array}$ & $C_{c}$ & $e_{0}$ & $\begin{array}{c}p_{c}^{\prime} \\
(\mathbf{k P a})\end{array}$ & $\begin{array}{c}\sigma^{\prime} \\
(\mathbf{k P a})\end{array}$ & $\begin{array}{c}\gamma_{i} \\
\left(\mathbf{k N} / \mathbf{m}^{3}\right)\end{array}$ \\
\hline $0.0-1.75$ & 6.4 & $k_{h 0} / 1.5$ & 0.71 & 3.10 & 60 & 4.88 & 16.5 \\
\hline $1.50-2.50$ & 5.2 & $k_{h 0} / 1.5$ & 0.71 & 3.10 & 55 & 12.25 & 15.0 \\
\hline $2.50-5.50$ & 5.2 & $k_{h 0} / 1.5$ & 1.38 & 3.00 & 50 & 22.25 & 15.0 \\
\hline $5.50-6.50$ & 3.1 & $k_{h 0} / 1.5$ & 1.38 & 3.00 & 44 & 32.50 & 15.5 \\
\hline $6.50-8.00$ & 3.1 & $k_{h 0} / 1.5$ & 0.71 & 1.95 & 51 & 39.38 & 15.5 \\
\hline $8.00-10.00$ & 1.3 & $k_{h 0} / 1.5$ & 0.71 & 1.82 & 60 & 49.50 & 16.0 \\
\hline $10.00-12.00$ & 0.6 & $k_{h 0} / 1.5$ & 0.83 & 1.86 & 73 & 61.50 & 16.0 \\
\hline $12.00-14.00$ & 0.6 & $k_{h 0} / 1.5$ & 0.83 & 1.89 & 86 & 73.50 & 16.0 \\
\hline $14.00-16.00$ & 0.6 & $k_{h 0} / 1.5$ & 0.83 & 1.86 & 97 & 85.50 & 16.0 \\
\hline $16.00-18.00$ & 0.6 & $k_{h 0} / 1.5$ & 0.83 & 1.86 & 110 & 97.50 & 16.0 \\
\hline
\end{tabular}

Note: $\gamma_{i}=$ unit weight of soil;

From $\mathrm{CK}_{0} \mathrm{U}$ triaxial tests (Indraratna and Balasubramaniam. 1993), the relevant soil properties, including compressibility indices, soil unit weights, initial void ratios, pre-consolidation pressure and permeability coefficients have been obtained. The embankment load was applied in two stages. During the first construction stage, the embankment was raised to a height of $2.57 \mathrm{~m}$ within 14 days. After a rest period of 105 days, an additional fill layer having a compacted unit weight of $20.5 \mathrm{kN} / \mathrm{m}^{3}$, was placed in 24 days, until the embankment reached a height 
of $4.74 \mathrm{~m}$ (Indraratna et al. 2005c).

Figure 3 shows the loading stages and the comparison between the field data, the current model predictions and the previous analysis by Indraratna et al. (2005c). In the analysis, for the second construction stage, the initial in-situ effective stress and the initial coefficient of horizontal and vertical consolidation were determined at the end of Stage One. The difference in the surface settlement at the embankment centreline (Fig. 3c), between the current analysis and the solution proposed by Indraratna et al. (2005c), solution is significant during 50 to 200 days. The initial and final settlements show marginal difference between these two methods. The solution by Hansbo (1981) does not show good agreement with field measurements except for the period of 100 to 150 days. The predicted excess pore water pressures agree well with the measured result beneath the embankment at a depth of $11.2 \mathrm{~m}$ below ground surface, and at a location of $0.65 \mathrm{~m}$ away from the centreline (Figure $3 \mathrm{~b}$ ). This verified that the difference between the free strain and equal strain theories is small.

Figure 4 shows the difference between the degree of consolidation based on excess pore water pressure dissipation $\left(U_{p}\right)$ and the settlement $\left(U_{s}\right)$ with different construction time factor $T_{v c}$, respectively. For the same time factor $\left(T_{v}\right), U_{p}$ is always less than $U_{s}$, similar to the one-dimensional nonlinear consolidation theory obtained by Cai et al. (2007), Geng et al. (2006) and Xie et al. (2002). This also shows that the settlement based on $U_{s}$ occurs at a slightly higher rate than the settlement based on $U_{p}$. The differences between linear and nonlinear solutions increase with the increase in the rate of the construction time factor $T_{v c}$. For the degree of consolidation defined by the settlement $\left(U_{s}\right)$, the nonlinear model under constant load is the same as the linear model. However, for a given time factors $\left(T_{v}\right)$ the degree of consolidation defined by the excess pore water pressure $\left(U_{p}\right)$, the nonlinear model predicts $U_{p}$ under constant load is smaller than the linear solution.

\section{CONCLUSIONS}

An explicit rigorous analytical solution is derived based on the free strain theory for the case of nonlinear radial consolidation. The nonlinear model results provide a more accurate prediction when compared to the linear model. Considering the nonlinear characteristics of the soil, the degree of consolidation defined by pore water pressure $\left(U_{p}\right)$ is quite different from the degree of consolidation defined by settlement $\left(U_{s}\right)$. It is further found that $U_{p}$ is less than $U_{s}$, which is true of typical soft soils. 


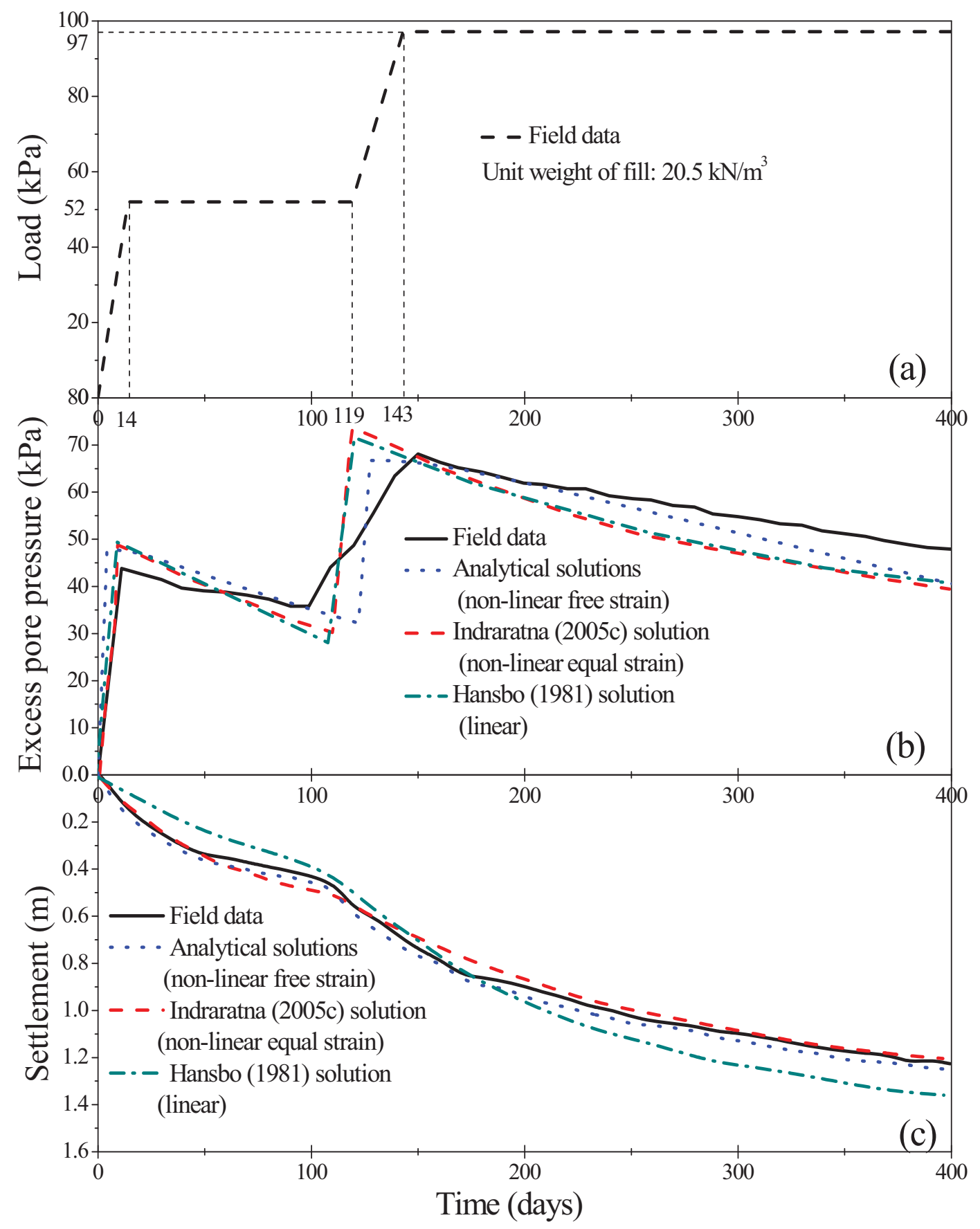

Figure 3. (a) Stages of loading; (b) Comparison of excess pore water pressure predicted using different theoretical with field data; (c) Comparison of settlement predicted using different theoretical methods wit field observation. 


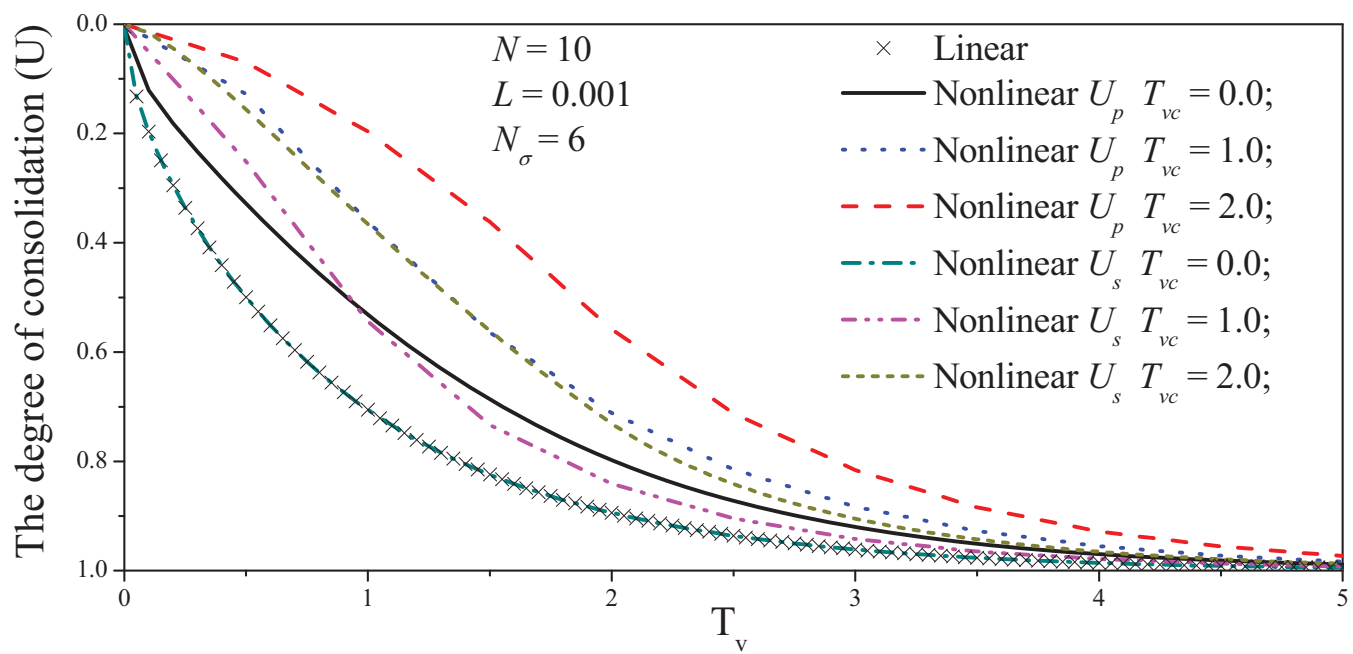

Figure 4. Difference degree of consolidation between $U_{p}$ and $U_{s}$ with different construction time factor $T_{v c}$ under ramp loading.

A selected full scale embankment on soft soil constructed at the Muar Coastal Plain was analysed here. The centreline settlements and excess pore-water pressure of the field were predicted and compared to the available field data. The proposed non-linear solutions give a more accurate settlement and excess pore water pressure prediction, although the initial and finial settlements show insignificant differences between the linear and non-linear solution. It can be concluded that the system of PVD with the surcharge preloading is a useful method for accelerating radial consolidation. The rigorous analytical solutions based on the free strain theory presented here are useful to predict the performance of soft clay installed by PVDs. The difference between the free strain and equal strain theories is insignificant.

\section{ACKNOWLEDGEMENT}

The Authors gratefully acknowledge the financial assistance from Australian Research Council. The authors appreciate the support of the Malaysian Highway Authority and the Airports Authority of Thailand, and the initial work executed by Prof. Indraratna's PhD students in this area.

\section{REFERENCES}

Barron, R. A. (1948). “Consolidation of Fine-grained Soils by Drain Wells.” Trans. ASCE, 113, 718-742.

Basak, P., and Madhav, M. R. (1978). "Analytical Solutions of Sand Drain Problem." Journal of Geotechnical engineering, ASCE, 104(GT1), 129-135.

Cai, Y. Q., Geng, X. Y., and Xu, C. J. (2007). "Solution of One-dimensional Finite-strain Consolidation of Soil with Variable Compressibility under Cyclic Loadings.” Computers and Geotechnics, 34, 31-40. 
Davis, R. E., and Raymond, G. P. (1965). “A Non-linear of Consolidation.” Geotechnique, 15(2), 161-173.

Geng, X. Y., Cai, Y. Q., and Xu, C. J.(2006). “Non-linear Consolidation Analysis of Soil with Variable Compressibility and Permeability under Cyclic Loadings." Int. J. Numer. Anal. Meth. Geomech, 30, 803-821.

Geng, X. Y. (2008). "Non-linear consolidation of soil with vertical and horizontal drainage under time-dependent loading". Proceeding of 2008 International Conference on Advanced Computer Theory and Engineering, 800-804.

Indraratna, B., Balasubramaniam, A. S., and Ratnayake, A.M.P. (1994). "Performance of embakment stabilised with vertical drains on soft clay". Journal of Geotechnical Engineering, ASCE, 120(2): 257-273.

Indraratna, B., Sathananthan, I., Rujikiatkamjorn C., and Balasubramaniam, A. (2005a). "Analytical and numerical modelling of soft soil stabilized by PVD incorporating vacuum preloading." Int. J. of Geomechanics, ASCE, 5(2), 114-124.

Indraratna, B., Rujikiatkamjorn, C., and Sathananthan, I. (2005b) "Analytical and numerical solutions for a single vertical drain including the effects of vacuum preloading." Canadian Geotechnical Journal, 42, 994-1014.

Indraratna, B., Rujikiatkamjorn, C., and Sathananthan, L. (2005c). "Radial consolidation of clay using compressibility indices and varying horizontal permeability." Canadian Geotechnical Journal, 42, 1330-1341.

Indraratna, B., and Balasubramaniam, A. S. (1993) "Authors' closure: performance of test embankment constructed to failure on soft clay." Journal of Geotechnical Engineering, ASCE, 119(9): 1321-1329.

Lekha, K. R., Krishnaswamy, N. R., and Basak, P. (1998). "Consolidation of Clay by Sand Drain under Time-dependent Loading.” J. Geo. Geoen. Engine. ASCE, 124(1), 91-94.

Rujikiatkamjorn, C., and Indraratna, B. (2007). "Analytical solutions and design curves for vacuum-assisted consolidation with both vertical and horizontal drainage." Canadian Geotechnical Journal, 44, 188-200.

Rujikiatkamjorn, C., Indraratna, B., and Chu, J. (2009). “2D and 3D Numerical Modeling of Combined Surcharge and Vacuum Preloading with Vertical Drains.” International Journal of Geomechanics, ASCE, 8(2), 144-156.

Moshier, S. L. B. (1989). "Methods and programs for mathematical functions." Chichester: Ellis Horwood.

Olson, R. E. (1977). "Consolidation under Time-dependent Loading." J. Geotech. Engng Div., ASCE. 103. No. GT1, 55-60.

Xie, K. H., Xie, X. Y., and Jiang, W. (2002). "A Study on One-dimensional Nonlinear consolidation of double-layered Soil." Computers and Geotechnics, 29, 151-168.

Yoshikuni, H., and Nakanodo, H. (1974). "Consolidation of soils by vertical drain wells with finite permeability." Soils and Foundations, 14(2), 35-46.

Zhu, G., and Yin, J. H. (2001). "Consolidation of Soil with Vertical and Horizontal Drainage under Ramp Load.” Geotechnique, 51(4), 361-367. 